\title{
Ex Vivo Study Comparing Three Cold Atmospheric Plasma (CAP) Sources for Biofilm Removal on Microstructured Titanium
}

\author{
Saskia Preissner,,${ }^{a,}{ }^{,}$Ann Cathrin PoehImann, ${ }^{a}$ Andreas Schubert, ${ }^{b}$ Antje \\ Lehmann, ${ }^{\mathrm{c}}$ Thomas Arnold, ${ }^{\mathrm{c}}$ Olaf Nell, ${ }^{\mathrm{d}} \&$ Stefan Rupf ${ }^{\mathrm{d}}$ \\ aCharité Universitätsmedizin Berlin, Berlin, Germany; 'IZI Fraunhofer, Leipzig, Germany; \\ cIOM Leipzig, Leipzig, Germany; dUniversity Homburg, Homburg, Germany \\ *Address all correspondence to: Saskia Preissner, Charité Universitätsmedizin Berlin, Assmannshauser Str. 4-6 Berlin,
Germany; Tel.: 4930450562675, E-mail: saskia.preissner@charite.de
}

\begin{abstract}
The aim of the present experimental study was to test three different plasma sources on the removal of $72 \mathrm{~h}$ oral biofilms. It was hypothesized that cold atmospheric plasma (CAP) lowers biofilm coverage significantly. In vivo biofilms were formed on sand-blasted/acid-etched titanium discs $(n=40)$ mounted on splints worn for $72 \mathrm{~h}$ by eight volunteers. Specimens were randomly divided into five groups: CAP I received indirect plasma application, CAP II received direct plasma application, CAP III received microwave-driven pulsed plasma application $(90 \mathrm{~s}$ each). The chlorhexidine (CHX) group was cleaned with a curette and rinsed with CHX. Biofilms of a control group received no treatment. After treatment, all specimens were rinsed for $10 \mathrm{~s}$ using a dental air/water spray ( 2 bar). The vitality of microorganisms was detected by cultivation on agar plates for $24 \mathrm{~h}$ and $48 \mathrm{~h}$. The presence of biofilms and their quantity on the titanium samples was investigated by fluorescence microscopy (FM) using live/dead staining. A biofilm's quality was analyzed by scanning electron microscopy (SEM). All treated samples showed a reduced growth on agar plates compared with the control group. FM analysis showed significantly lowered biofilm coverage in all treatment groups compared with the negative control group $(t$ test, $p<0.05)$. Within the plasma treatment groups, there was a significant difference between CAP II and CAP III $(p=0.032)$. SEM showed disintegrated biofilms in all test groups. CAP reduces and disintegrates oral biofilms. Adjuvant application plasma could lead to more effective antimicrobial therapies for peri-implantitis.
\end{abstract}

KEY WORDS: cold atmospheric plasma, peri-implantitis, direct plasma, indirect plasma

\section{INTRODUCTION}

Plasma is an ionized gas and is referred to as the fourth state of matter. ${ }^{1,2}$ Plasma consists of various portions of electrons, neutrons, and ionized atoms, as well as neutral or charged molecules. It can be generated under normal pressure conditions in so-called plasma jet sources by adding energy in the form of heat, microwaves, radio frequency, or pulsed direct current high voltage to a gas stream. ${ }^{2}$

Its various "effect-cocktail" on biological material or tissues is due to charged particles, chemically reactive species such as reactive oxygen species and reactive nitrogen species, heat, and UV radiation. ${ }^{1,3-5}$ The current therapeutic application spectrum of plasma in medicine reaches from well-established sterilization of surgical instru- 
ments, implants, and consumables, coagulation, ablation, and vaporization of tissues to its more recent utilization as antimicrobial therapy, stimulation of wound healing, and tumor therapy. ${ }^{1,6-10}$ Exposure to cold atmospheric plasma (CAP) effectively leads to inactivation and destruction of a variety of even multi-resistant bacteria and bacterial biofilms, as wells as spores, fungi, and viruses. ${ }^{8,9,11-17}$ To date, no resistance against plasma is known. ${ }^{9,18,19}$

Worldwide, the number of inserted dental implants used as an established therapy for missing teeth is increasing. ${ }^{20}$ In many cases, dental implants are the only way to restore missing molar teeth and toothless jaws in a fixed prosthetic manner. ${ }^{21}$

Peri-implant diseases are among the most common complications after dental implantation. ${ }^{20,22}$ Due to their clinical phenotype, peri-implant diseases are categorized in reversible inflammatory reactions in the soft tissues as mucositis and irreversible, progressive inflammatory reactions with loss of supporting bone as peri-implantitis. ${ }^{21-24} \mathrm{Up}$ to $56 \%$ of inserted dental implants develop peri-implantitis. ${ }^{25}$ Until now, there has been no ideal therapy for these cases. ${ }^{20,21}$

The etiological factor for the development of peri-implant inflammations is the formation of oral biofilms on the surface of intraosseus dental implants and on their supraconstructions such as crowns, which are exposed to the oral environment. ${ }^{21,24}$ Biofilms are formed as microbial communities on the interface of hard surface and biological liquids and consist of bacteria, extracellular polysaccharid matrix, proteins, and nuclein acids. The development and maturation of oral biofilms proceeds in different stages. ${ }^{26,27}$ Within minutes, a so-called pellicle layer is formed out of adsorbed salivary proteins, glycoproteins, and mucin. In the next minutes to hours, bacteria adhere on the pellicle's surface, divide, and recruit more planktonic bacterial cells. A three-dimensional multilayer biofilm is formed by bacterial growth, co-adherence of further bacterial species, and maturation of the extracellular matrix due to bacterial glycosyltransferases synthesizing water-soluble and -insoluble glucans. ${ }^{26}$

The exceptional biocompatibility of titanium as a dental implant material makes it ideal for osteoblast and fibroblast adsorption, but also for biomolecular pellicles and thus accumulation of microorganisms on their surfaces. ${ }^{27,28}$ Without therapy, bone degeneration caused by peri-implantitis can lead to implant loss and may have further systemic effects on the cardiovascular system due to bacteria reaching the bloodstream. . $^{20,21,29,30}$

Traditional therapies aim at the destruction of oral biofilms on infected implant surfaces. ${ }^{20,21}$ Conservative, non-surgical therapy options are mechanical cleaning, smoothing, and polishing with curettes of different materials (Teflon, carbon, plastic, titanium), ultrasonic systems, air-polishing with water-soluble powders or laser treatment, often in combination with antimicrobial agents or antibiotics. ${ }^{20,21,31}$ However, none of these therapeutic procedures are able to arrest peri-implantitis. Apart from maximum invasive explantation, which also causes large bone defects that often make re-implantation impossible, no reliable therapy for peri-implant diseases is available to date. ${ }^{20,21,23}$ Accordingly, there is a great technical and therapeutical interest in methods for the decontamination of titanium surfaces. 
The novel field of plasma medicine and the local application of CAP could offer an attractive clinical concept for inactivation and destruction of adherent bacteria and bio-

film and its capability in this regard has been shown in several studies. ${ }^{8,9,12-14,16,17,19}$ Using a sequential plasma-water spray-plasma treatment, it was possible to remove oral $72 \mathrm{~h}$ biofilms completely while preserving the titanium microstructure..$^{32,33}$

The aim of this experimental study was to compare three different plasma sources for removal of $72 \mathrm{~h}$ biofilms formed in situ from the microstructure of sand-blasted/acidetched titanium dental implant surfaces. It was hypothesized that using CAP and water spray in a simplified two-step sequence leads to significant lower biofilm coverage on titanium.

\section{MATERIALS AND METHODS}

\section{A. In Vivo Biofilm Development}

Eight healthy volunteers (four male, four female, mean age: 26.8 years) wore individual, custom-made maxillary plastic splints with five micro-structured titanium specimens (Dentsply Implants, Mannheim, Germany) placed on the buccal sides of the premolar and molar teeth for $72 \mathrm{~h}$. The titanium discs ( $n=40$, sand-blasted, acid-etched, titanium grade 2 , d: $5 \mathrm{~mm}$, h: $1 \mathrm{~mm}$, mean roughness: $1.96 \mu \mathrm{m}$ ) were fixed with silicone impression material (President light body, Coltene, Switzerland) on the splints for intraoral biofilm formation. ${ }^{8}$ The study protocol was approved by the ethical committee of Charite Universitätsmedizin Berlin (EA4/090/017) and written informed consent was obtained from all participants.

During the $72 \mathrm{~h}$ exposure time, the volunteers followed their usual drinking and eating habits, but avoided biofilm-formation-inhibiting products such as tea and red wine. No mechanical cleaning or chemical products for plaque control such as toothpaste or mouth rinses were used. Splints were removed for meals or drinking only and then stored in a humid compartment (water-soaked cellulose fabric in an oxygen-proof plastic container).

After biofilm formation, the titanium discs were placed in a humid container such as described above and stored in a cool environment $\left(7^{\circ} \mathrm{C}\right)$ until further treatment.

\section{B. Anti-Biofilm Treatment}

The titanium discs covered with $72 \mathrm{~h}$ in situ biofilms were rinsed ex vivo with sterile saline solution $(0.9 \%)$ for $10 \mathrm{~s}$. Titanium discs from each volunteer were randomly divided into five groups of eight specimens each. Each treatment consisted of two steps: (1) the plasma or mechano-antimicrobial procedure and (2) air-water spraying.

\section{Plasma Treatment and Mechano-Antimicrobial Procedure}

Indirect CAP (CAP I) was applied for $90 \mathrm{~s}$ by constantly moving the plasma jet (kINPen ${ }^{\circledR}$ MED, Neoplas Tools GmbH, Greifswald, Germany ${ }^{25,26}$ ), fed with $4.3 \mathrm{sL}^{*} \mathrm{~min}^{-1}$ 
argon in a perpendicular position and within approximately $3 \mathrm{~mm}$ distance from the specimens' surface.

Direct plasma (CAP II) was generated using the PlasmaDerm FLEX 9060 (Cinogy, Duderstadt, Germany). Duration of voltage pulses was $10 \mu$ s at amplitudes up to $10 \mathrm{kV}$ and a repetition rate of $300 \mathrm{~Hz}$. A mean input power was defined as $450 \mathrm{~mW}$ according to the manufacturer's information. Plasma was applied for $90 \mathrm{~s}$ while the electrode's surface ensured a constant gap of $2 \mathrm{~mm}$ filled with ambient air.

Microwave-driven pulsed plasma jet (CAP III), described in detail by Lehmann et al., ${ }^{1}$ was generated by means of the following parameters: He flow $2.0 \mathrm{slm}, \mathrm{N}_{2}$ flow $0.3 \mathrm{slm}$, pulse power $200 \mathrm{~W}$, pulse width $5 \mu \mathrm{s}$, pulse repetition frequency $4.9 \mathrm{kHz}$, resulting in an average input power of $5 \mathrm{~W}$. For a meandering movement a three-axis linear motion system (Steinmeyer MC-G047) was used, with a scanning speed of $8 \mathrm{~mm} / \mathrm{s}$, line spacing of $0.1 \mathrm{~mm}$, and working distance of $3 \mathrm{~mm}$ from the sample surface; the plasma jet was applied for $90 \mathrm{~s}$ on each specimen.

For the mechano-antimicrobial procedure (positive control, $n=8$ ), specimens were mechanically cleaned with a plastic curette (Hu-Friedy, Frankfurt am Main, Germany) for $10 \mathrm{~s}$ and placed in $2 \mathrm{~mL}$ of $0.2 \%$ chlorhexidine (CHX) for $90 \mathrm{~s}$ (Chlorhexamed forte, GSK, Berlin, Germany).

\section{Air-Water Spraying}

After treatment with CAP or mechano-antimicrobial procedure or no treatment (negative control, $n=8$ ) specimens were air-water sprayed for $10 \mathrm{~s}$ using a dental air/water spray unit (U 3000 EX, Ultradent, Brunnthal, Germany). The input water pressure was set to 2 bar.

\section{Microbiology}

All titanium discs $(n=40)$ were inoculated for $5 \mathrm{~s}$ twice on brain heart infusion blood agar (Sigma-Aldrich, Taufkirchen, Germany) on Rodac plates (d: 50mm, Merck, Darmstadt). Eight further fresh specimens without biofilm were used as controls. After inoculation, agar plates were incubated at $37^{\circ} \mathrm{C}\left(5 \% \mathrm{CO}_{2}\right)$. The plates were examined after 24 $\mathrm{h}$ and $48 \mathrm{~h}$ of incubation.

\section{Fluorescence Microscopy}

The existence and amounts of biofilms on the titanium discs were assessed by fluorescence microscopy using live/dead staining (Live/Dead BacLight Bacterial Viability Kit L7012, Molecular Probes, Carlsbad, CA, USA). Eight more specimens without biofilms were used as controls. The live/dead stain was prepared by diluting $1 \mu \mathrm{L}$ of SYTO 9 and $1 \mu \mathrm{L}$ of propidium iodide in $1 \mathrm{~mL}$ of $\mathrm{NaCl}$ solution and stored for $60 \mathrm{~min}$ on ice cubes in a dark container. The titanium specimens were placed in 24 -well plates and $10 \mu \mathrm{L}$ of the reagent mixture was added to each 
well, followed by incubation at room temperature in the dark for $15 \mathrm{~min}$. Specimens were placed carefully on a glass slide and covered with mounting oil and a glass cover slide.

The biofilm analysis was performed using a reverse light fluorescence microscope (Leitz DMR, Leica, Wetzlar, Germany) provided with a digital camera (AxioCam MRm Rev. 3, Carl Zeiss Microimaging, Göttingen, Germany) and corresponding filter sets using the image processing software ZEN 2.3 (Carl Zeiss Microimaging).

The biofilm coverage of the specimens was captured by taking images of the titanium surface in two randomly chosen areas of each titanium sample. Red and green color images were taken separately. Medians of red and green fluorescence intensities were calculated using the 0-255 gray scale and total fluorescence and percentage of areas without fluorescence were ascertained by red/green overlays. Continuous data with median and interquartile ranges were summarized (25-75th percentile).

\section{E. Scanning Electron Microscopy (SEM)}

The biofilm's quality was analyzed by SEM on one randomly selected specimen of each subgroup. A titanium disc without biofilm served as a control. The specimens were fixed in glutaraldehyde $(2.5 \%$ in phosphate-buffered saline [PBS]; PAA laboratories $\mathrm{GmbH}$, Pasching, Austria) for $50 \mathrm{~min}$, followed by rinsing four times for $10 \mathrm{~min}$ in PBS. Subsequently, the specimens were dehydrated using an increasing series of ethanol rinses (50-90\% $10 \mathrm{~min}$ each; 96\% $2 \times 10 \mathrm{~min})$. Last, the samples were dried in 1,1,1,3,3,3-hexamethyl-disilazane (HMDS, Acros Organics, Geel, Belgium). HMDS was vaporized in a clean bench at room temperature. All specimens were mounted on SEM sample stubs (Plano, Wetzlar, Germany), followed by platinum sputtering. SEM analysis was performed in an FEI XL30 ESEM FEG (FEI Company, Eindhoven, The Netherlands) at magnifications of $1000 \times$ to $10,000 \times$. Each subgroup's titanium surface was scanned for biofilm remnants or bacteria as well as structural changes caused by plasma treatments in triplicates.

\section{F. Statistical Analysis}

Statistical analysis was performed using SPSS 24 (IBM, Armonk, IL, USA).

\section{RESULTS}

All test groups showed a lowered growth on Rodac plates (Figs. 1 and 2) compared with the control group. The fluorescence microscopy analysis (Fig. 3) showed significantly lowered biofilm coverage in all test groups compared with the control group ( $t$ test, $p<$ $0.05)$ (Figs. 4 and 5). Within the test groups, the only significant difference was between CAP II and CAP III $(p=0.032)$. SEM confirmed these results, showing disintegrated biofilms in all test groups (Table 1).

Volume 9, Issue 1, 2019 


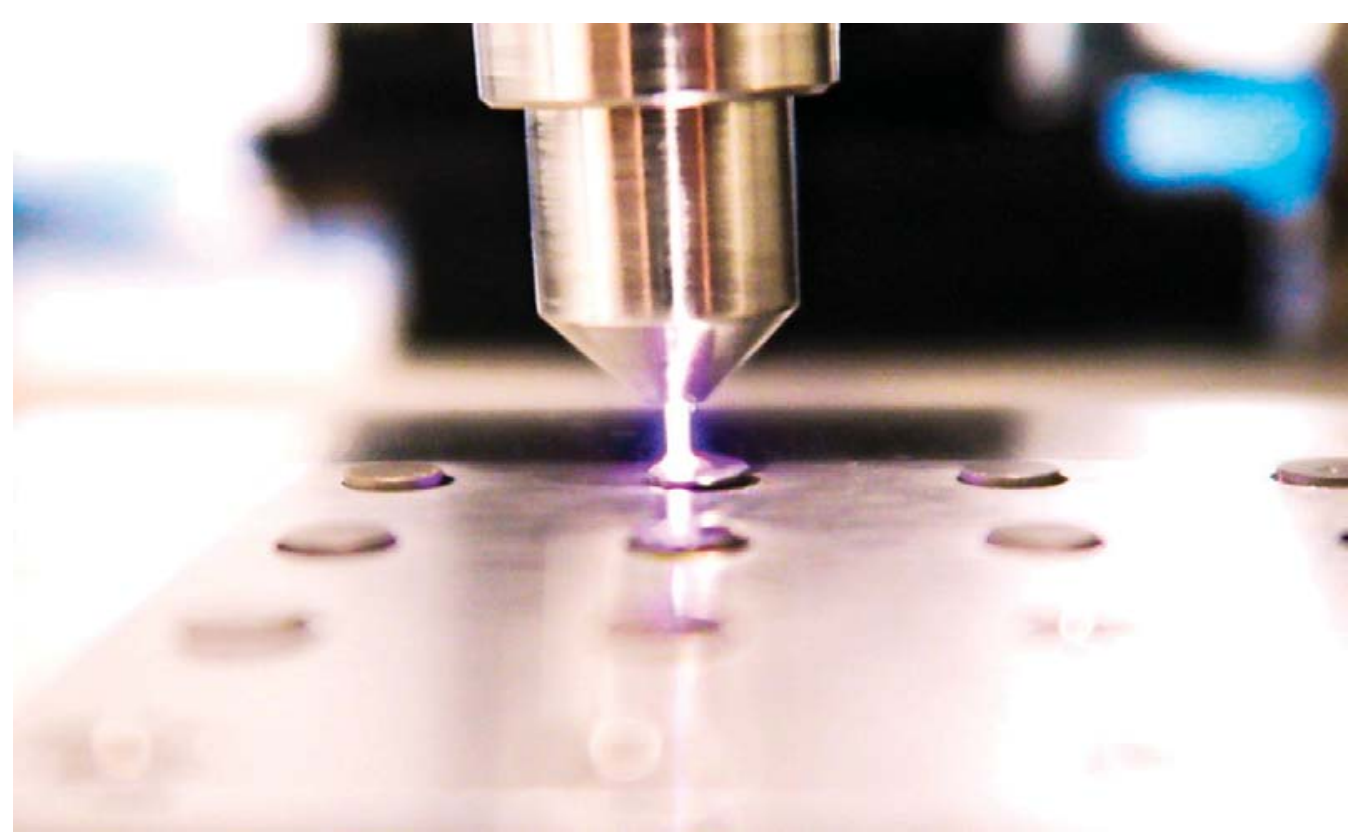

FIG. 1: Microwave-driven pulsed plasma, IOM source (CAP III), on titanium discs

\section{DISCUSSION}

To the best of our knowledge, this is the first study to compare three different CAP sources in terms of disintegrating multispecies in vivo-formed oral biofilm on infected titanium surfaces. It was hypothesized that exposure of CAP leads to significant lower biofilm coverage defined by more effective disintegration and inactivation of ex vivo multispecies biofilms.

It was demonstrated that all three CAPs, indirect plasma kINPen ${ }^{\circledR}$ MED, direct plasma PlasmaDerm FLEX 9060, and microwave-driven pulsed indirect plasma, led to significant reduction in vitality and coverage of $72 \mathrm{~h}$ in vivo-developed biofilm on titanium discs $(t$ test, $p<0.05)$. Furthermore, it was found that the effectiveness of disintegrating biofilms with all applied plasma sources was comparable to mechanical debridement combined with $0.2 \%$ CHX treatment. The experimental microwave plasma source ${ }^{34}$ reduced the biofilms significantly more than the direct plasma source $(p=0.032)$. None of the other groups was significantly different in biofilm removal. Our hypothesis could therefore only be partially confirmed. In a former similar ex vivo study, ${ }^{32}$ it was possible to totally remove biofilms on titanium specimens. These results differ from those in our present study. In contrast to our current procedure, both the CAP and the air-water spray were used twice. This resulted in a considerable additional expenditure of time. However, because the procedure in our current study also led to a considerable biofilm reduction and biofilm disinfection, 


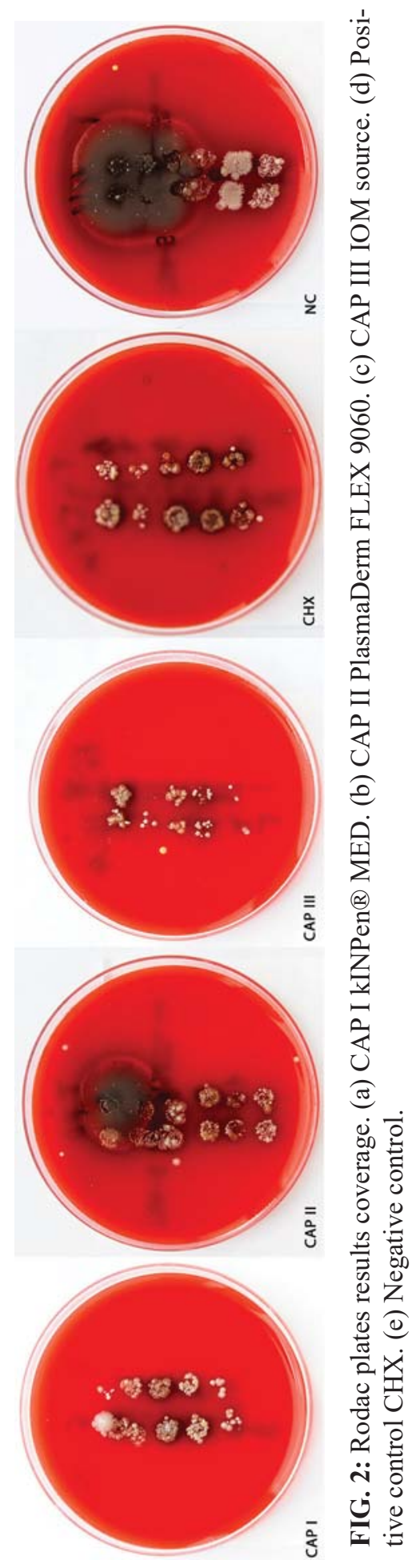

Volume 9, Issue 1, 2019 


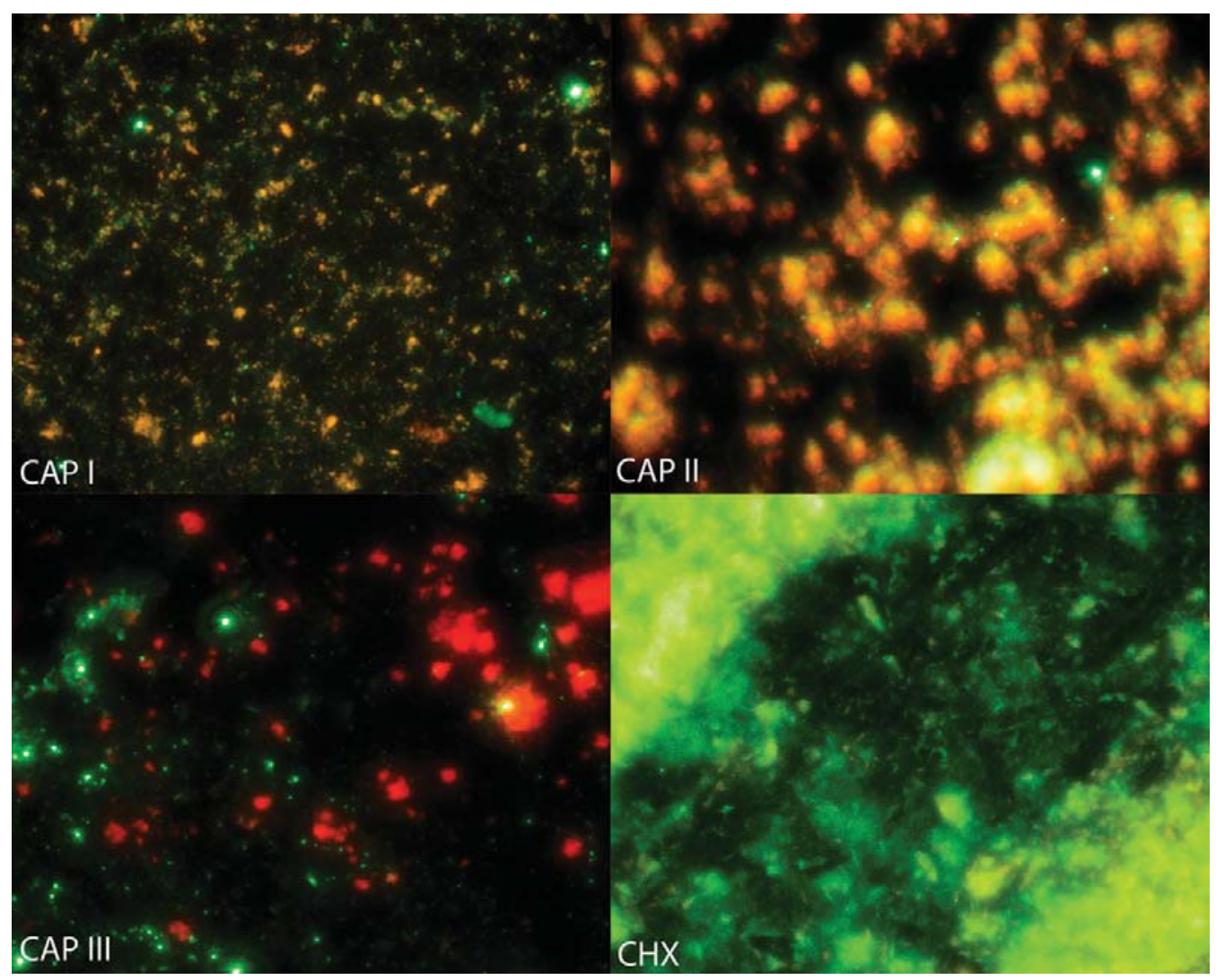

FIG. 3: Fluorescence microscopy results biofilm coverage. (a) CAP I kINPen ${ }^{\circledR}$ MED. (b) CAP II PlasmaDerm FLEX 9060. (c) CAP III IOM source. (d) Positive control CHX.

parameters are available that can be adapted to the corresponding clinical requirements of biofilm removal or biofilm disinfection.

Another study demonstrated that indirect plasma (kINPen ${ }^{\circledR}$ MED) removed artificial biofilm in vitro more effectively than application of a diode 1 laser ${ }^{35}$ and in vivo-developed biofilm on extracted teeth could been removed in the analog dimension as by mechanical cleaning. ${ }^{36}$ In another in vitro study, a CAP application of $600 \mathrm{~s}$ to Pseudomonas aeruginosa monospecies biofilms could achieve higher antimicrobial reduction than treatment with $0.1 \% \mathrm{CHX} .{ }^{37}$ The results of these two studies also support our conclusion that CAP should not be used exclusively, but rather adjunctively.

To optimize the material properties of titanium surfaces, studies could demonstrate an improved wettability as well as optimized growth behavior of fibroblasts and osteoblasts after plasma treatment. ${ }^{38,39}$ Additionally, an optimized osseointegration of implants after 6 weeks was found after treatment with CAP in a dog 


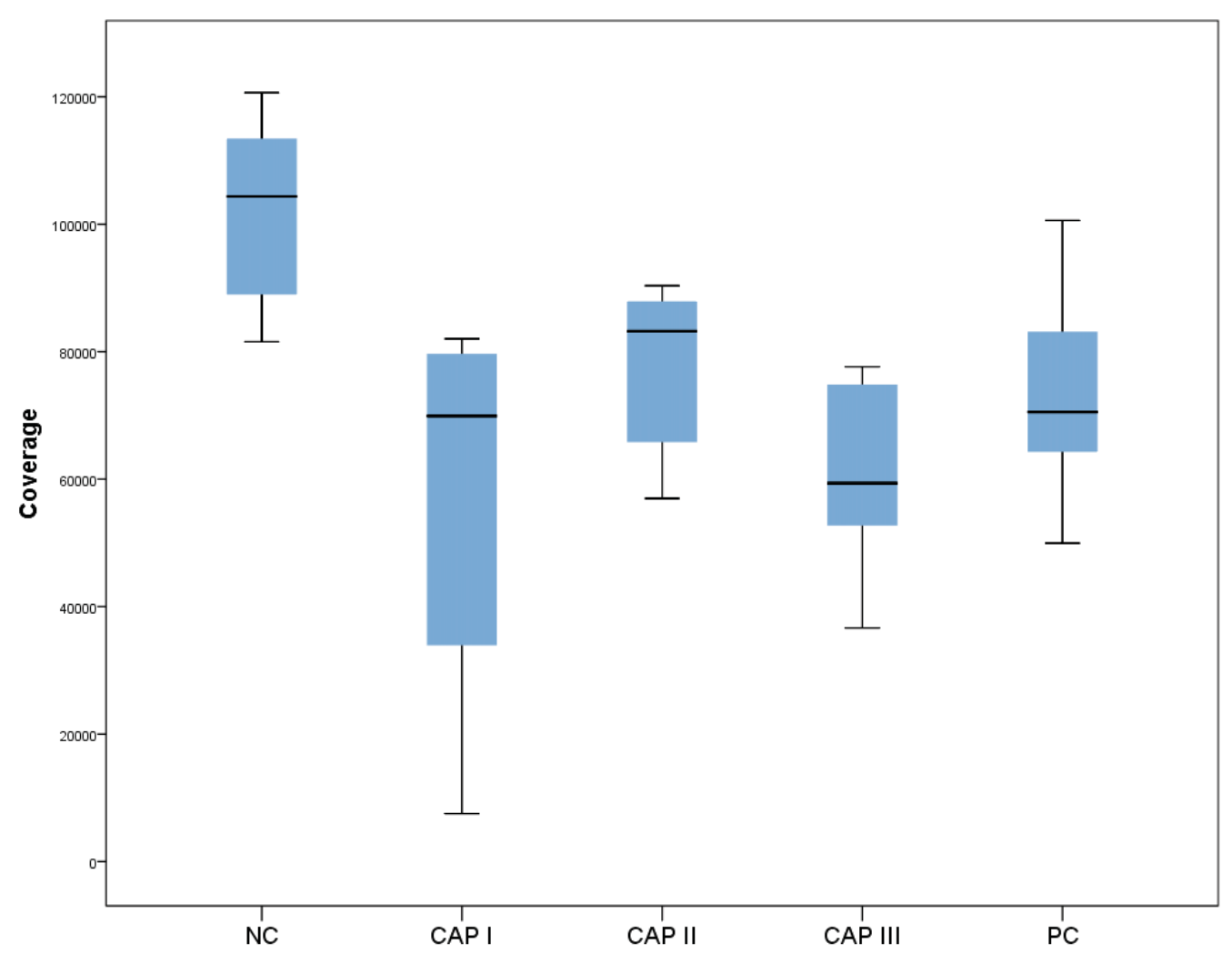

FIG. 4: Box plots results of biofilm coverage

model. ${ }^{40}$ Beyond the regeneration of bone structures, plasma could have the potential to accelerate wound healing of peri-implant inflammations. ${ }^{7,41}$ Until now, no resistances of specific microbes or permanent unwanted effects are known for CAP treatment. $7,13,14,42-44$

In summary, the results of the present study demonstrate the potential of different CAP sources to reduce oral multispecies biofilms and to disinfect titanium surfaces for use in regenerative peri-implantitis therapy. In conjunction with the results of other studies, we assume that adjuvant application of CAP in combination with mechanical debridement and antimicrobial agencies leads to increased antimicrobial effectiveness and eliminates biofilm more effectively than mono-therapies. ${ }^{32,35,38}$ There is no method currently in existence that completely disinfects and eliminates biofilm on implant surfaces without destroying the material properties of the surface. Plasma treatment could represent a non-invasive, time-efficient therapy option. Further studies are necessary to investigate how adjunctive plasma biofilm treatment could be optimized.

Volume 9, Issue 1, 2019 


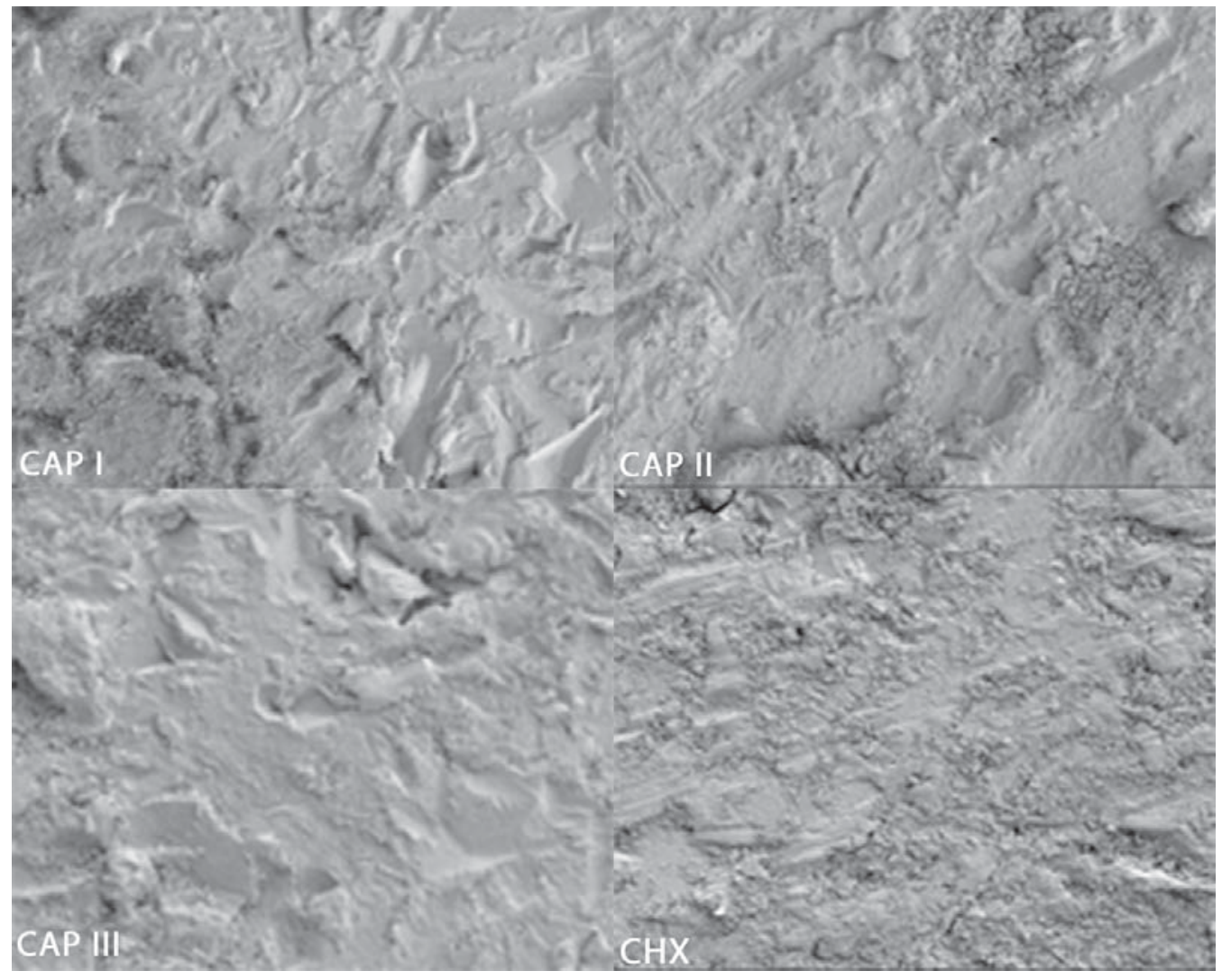

FIG. 5: SEM results of biofilm coverage. Magnification, 2000×, HV $1.0 \mathrm{kV}$, Spot 3.0, $50.0 \mu \mathrm{m}$. (a) SEM CAP I kINPen ${ }^{\circledR}$ MED. (b) SEM CAP II PlasmaDerm FLEX 9060. (c) SEM CAP III IOM source. (d) SEM positive control CHX.

\section{ACKNOWLEDGMENT}

The authors thank Dentsply Implants Friadent, Mannheim, Germany, for providing the implant discs.

TABLE 1: Results of culture, fluorescence microscopy, and SEM

\begin{tabular}{|l|c|c|c|c|}
\hline \multirow{2}{*}{} & \multicolumn{2}{|c|}{ Culture colonies } & Fluorescence microscopy \\
\cline { 2 - 3 } & Complete & Few & $\begin{array}{c}\text { SEM disintegrated biofilm } \\
\text { Yes/no }\end{array}$ \\
\hline CAP I & - & $\mathrm{X}$ & 72.77 & Yes \\
\hline CAP II & - & $\mathrm{X}$ & 86.83 & Yes \\
\hline CAP III & - & $\mathrm{X}$ & 69.49 & Yes \\
\hline CHX & - & $\mathrm{X}$ & 70.40 & Yes \\
\hline NC & $\mathrm{X}$ & - & 100.00 & No \\
\hline
\end{tabular}

$\mathrm{NC}$, negative control 


\section{REFERENCES}

1. Haertel B, von Woedtke T, Weltmann KD, Lindequist U. Non-thermal atmospheric-pressure plasma possible application in wound healing. Biomol Ther (Seoul). 2014;22(6):477-90.

2. Metelmann HR, von Woedtke T, Weltmann KD. Plasmamedizin: Kaltplasma in der medizinischen Anwendung. 2016.

3. Arjunan KP, Sharma VK, Ptasinska S. Effects of atmospheric pressure plasmas on isolated and cellular DNA-a review. Int J Mol Sci. 2015;16(2):2971-3016.

4. Laroussi M, Kong MG, Morfill G, Stolz W. Plasma medicine: Applications of low-temperature gas plasmas in medicine and biology. Cambridge: Cambridge University Press; 2012.

5. Von Woedtke T RS, Masur K, Weltmann KD. Plasmas for medicine. Phys Rep. 2013;530:291-320.

6. Babington P, Rajjoub K, Canady J, Siu A, Keidar M, Sherman JH. Use of cold atmospheric plasma in the treatment of cancer. Biointerphases. 2015;10(2):029403.

7. Isbary G, Morfill G, Schmidt HU, Georgi M, Ramrath K, Heinlin J, Karrer S, Landthaler M, Shimizu T, Steffes B, Bunk W, Monetti R, Zimmermann JL, Pompl R, Stolz W. A first prospective randomized controlled trial to decrease bacterial load using cold atmospheric argon plasma on chronic wounds in patients. Br J Dermatol. 2010;163(1):78-82.

8. Rupf S, Lehmann A, Hannig M, Schafer B, Schubert A, Feldmann U, Schindler A. Killing of adherent oral microbes by a non-thermal atmospheric plasma jet. J Med Microbiol. 2010;59:206-12.

9. Sharkey MA, Chebbi A, McDonnell KA, Staunton C, Dowling DP. Evaluation of the sensitivity of bacterial and yeast cells to cold atmospheric plasma jet treatments. Biointerphases. 2015;10(2):029507.

10. Southwood LL, Baxter GM. Instrument sterilization, skin preparation, and wound management. Vet Clin North Am Equine Pract. 1996;12(2):173-94.

11. Aboubakr HA, Williams P, Gangal U, Youssef MM, El-Sohaimy SA, Bruggeman PJ, Goyal SM. Virucidal effect of cold atmospheric gaseous plasma on feline calicivirus, a surrogate for human norovirus. Appl Environ Microbiol. 2015;81(11):3612-22.

12. Alkawareek MY, Algwari QT, Gorman SP, Graham WG, O'Connell D, Gilmore BF. Application of atmospheric pressure nonthermal plasma for the in vitro eradication of bacterial biofilms. FEMS Immunol Med Microbiol. 2012;65(2):381-4.

13. Klampfl TG, Isbary G, Shimizu T, Li YF, Zimmermann JL, Stolz W, Schlegel J, Morfill GE, Schmidt H-U. Cold atmospheric air plasma sterilization against spores and other microorganisms of clinical interest. Appl Environ Microbiol. 2012;78(15):5077-82.

14. Kvam E, Davis B, Mondello F, Garner AL. Nonthermal atmospheric plasma rapidly disinfects multidrug-resistant microbes by inducing cell surface damage. Antimicrob Agents Chemother. 2012;56(4):2028-36.

15. Maisch T, Shimizu T, Isbary G, Heinlin J, Karrer S, Klampfl TG, Li YF, Morfill G, Zimmermann JL. Contact-free inactivation of Candida albicans biofilms by cold atmospheric air plasma. Appl Environ Microbiol. 2012;78(12):4242-7.

16. Maisch T, Shimizu T, Li YF, Heinlin J, Karrer S, Morfill G, Zimmermann JL. Decolonisation of MRSA, S. aureus and E. coli by cold-atmospheric plasma using a porcine skin model in vitro. PLoS One. 2012;7(4):e34610.

17. Yoo EM, Uhm SH, Kwon JS, Choi HS, Choi EH, Kim KM, Kim KN. The study on inhibition of planktonic bacterial growth by non-thermal atmospheric pressure plasma jet treated surfaces for dental application. J Biomed Nanotechnol. 2015;11(2):334-41.

18. Mai-Prochnow A, Clauson M, Hong J, Murphy AB. Gram positive and Gram negative bacteria differ in their sensitivity to cold plasma. Sci Rep. 2016;6:38610.

19. Napp M, Daeschlein G, von Podewils S, Hinz P, Emmert S, Haase H, Spitzmueller R, Gümbel D, Kasch R, Jünger M. In vitro susceptibility of methicillin-resistant and methicillin-susceptible strains of Staphylococcus aureus to two different cold atmospheric plasma sources. Infection. 2016;44(4):531-7.

Volume 9, Issue 1, 2019 
20. Smeets R, Henningsen A, Jung O, Heiland M, Hammacher C, Stein JM. Definition, etiology, prevention and treatment of peri-implantitis—a review. Head Face Med. 2014;10:34.

21. Schwarz F, Becker J, Bach J, Bartsch K, Beck J, Blume M, Ighaut G, Kebschull M, Ritter L, Schlee M, Steisch M, Stiller M, Wolf T. S3-Leitlinie Die Behandlung peri-implantärer Infektionen an Zahnimplantaten. AWMF Online. 2016.

22. Lee CT, Huang YW, Zhu L, Weltman R. Prevalences of peri-implantitis and peri-implant mucositis: systematic review and meta-analysis. J Dent. 2017;62:1-12.

23. Lang NP, Berglundh T, Working Group 4 of Seventh European Workshop on Periodontology. Periimplant diseases: Where are we now? - Consensus of the Seventh European Workshop on Periodontology. J Clin Periodontol. 2011;38 Suppl 11:178-81.

24. Pesce P, Canullo L, Grusovin MG, de Bruyn H, Cosyn J, Pera P. Systematic review of some prosthetic risk factors for peri-implantitis. J Prosthet Dent. 2015;114(3):346-50.

25. Lindhe J1, Meyle J; Group D of European Workshop on Periodontology. Peri-implant diseases: Consensus report of the Sixth European Workshop on Periodontology. J Clin Periodontol. 2008;35(8 Suppl):282-5.

26. Hannig C, Hannig M. The oral cavity - a key system to understand substratum-dependent bioadhesion on solid surfaces in man. Clin Oral Investig. 2009;13(2):123-39.

27. Marsh PD. Dental plaque as a biofilm and a microbial community: Implications for health and disease. BMC Oral Health. 2006;6 Suppl 1:S14.

28. Subramani K, Jung RE, Molenberg A, Hammerle CH. Biofilm on dental implants: a review of the literature. Int J Oral Maxillofac Implants. 2009;24(4):616-26.

29. Horikawa T, Odatsu T, Itoh T, Soejima Y, Morinaga H, Abe N, Tsuchiya N, Iijima T, Sawase T. Retrospective cohort study of rough-surface titanium implants with at least 25 years' function. Int $\mathrm{J}$ Implant Dent. 2017;3(1):42.

30. de Araujo Nobre M, Malo P. Prevalence of periodontitis, dental caries, and peri-implant pathology and their relation with systemic status and smoking habits: Results of an open-cohort study with 22009 patients in a private rehabilitation center. J Dent. 2017;67:36-42.

31. Muthukuru M, Zainvi A, Esplugues EO, Flemmig TF. Non-surgical therapy for the management of peri-implantitis: a systematic review. Clin Oral Implants Res. 2012;23 Suppl 6:77-83.

32. Rupf S, Idlibi AN, Marrawi FA, Hannig M, Schubert A, von Mueller L, Spitzer W, Holtmann H, Lehmann A, Rueppell A, Schindler A. Removing biofilms from microstructured titanium ex vivo: a novel approach using atmospheric plasma technology. PLoS One. 2011;6(10):e25893.

33. Idlibi AN, Al-Marrawi F, Hannig M, Lehmann A, Rueppell A, Schindler A, Jentsch H, Rupf S. Destruction of oral biofilms formed in situ on machined titanium (Ti) surfaces by cold atmospheric plasma. Biofouling. 2013;29(4):369-79.

34. Lehmann A, Pietag F, Arnold T. Human health risk evaluation of a microwave-driven atmospheric plasma jet as medical device. Clin Plasma Med. 2017;7-8:16-23.

35. Preissner S, Wirtz HC, Tietz AK, Abu-Sirhan S, Herbst SR, Hartwig S, Pierdzioch P, Schmidt-Westhausen AM, Dommisch H, Hertel M. Bactericidal efficacy of tissue tolerable plasma on microrough titanium dental implants: An in-vitro-study. J Biophotonics. 2016;9(6):637-44.

36. Jablonowski L, Fricke K, Matthes R, Holtfreter B, Schluter R, von Woedtke T, Weltmann KD, Kocher T. Removal of naturally grown human biofilm with an atmospheric pressure plasma jet: An in-vitro study. J Biophotonics. 2017;10(5):718-26.

37. Matthes R, Hubner NO, Bender C, Koban I, Horn S, Bekeschus S, Weltmann KD, Kocher T, Kramer A, Assadian O. Efficacy of different carrier gases for barrier discharge plasma generation compared with chlorhexidine on the survival of Pseudomonas aeruginosa embedded in biofilm in vitro. Skin Pharmacol Physiol. 2014;27(3):148-57.

38. Duske K, Jablonowski L, Koban I, Matthes R, Holtfreter B, Sckell A, Nebe JB, von Woedtke T, Weltmann KD, Kocher T. Cold atmospheric plasma in combination with mechanical treat- 
ment improves osteoblast growth on biofilm covered titanium discs. Biomaterials. 2015;52: 327-34.

39. Lee JH, Kim YH, Choi EH, Kim KM, Kim KN. Air atmospheric-pressure plasma-jet treatment enhances the attachment of human gingival fibroblasts for early peri-implant soft tissue seals on titanium dental implant abutments. Acta Odontol Scand. 2015;73(1):67-75.

40. Danna NR, Beutel BG, Tovar N, Witek L, Marin C, Bonfante EA, Granato R, Suzuki M, Coelho PG. Assessment of atmospheric pressure plasma treatment for implant osseointegration. Biomed Res Int. 2015;2015:761718.

41. Daeschlein G, von Woedtke T, Kindel E, Brandenburg R, Weltmann K-D, Jünger M. Antibacterial activity of an atmospheric pressure plasma jet against relevant wound pathogens in vitro on a simulated wound environment. Plasma Processes and Polymers. 2010;7(3-4):224-30.

42. Han L, Patil S, Keener KM, Cullen PJ, Bourke P. Bacterial inactivation by high-voltage atmospheric cold plasma: influence of process parameters and effects on cell leakage and DNA. J Appl Microbiol. 2014;116(4):784-94.

43. Heinlin J, Zimmermann JL, Zeman F, Bunk W, Isbary G, Landthaler M, Maisch T, Monetti R, Morfill G, Shimizu T, Steinbauer J, Stolz W, Karrer S. Randomized placebo-controlled human pilot study of cold atmospheric argon plasma on skin graft donor sites. Wound Repair Regen. 2013;21(6):800-7.

44. Matthes R, Assadian O, Kramer A. Repeated applications of cold atmospheric pressure plasma does not induce resistance in Staphylococcus aureus embedded in biofilms. GMS Hyg Infect Control. 2014;9(3):Doc17.

Volume 9, Issue 1, 2019 
